\title{
Diferentes Visões Brasileiras sobre Tim Burton
}

CÁNEPA, Laura Loguercio (Org.). Tim Burton, Tim Burton, Tim Burton. São José dos Pinhais: Editora Estronho, 248 p., 2016.

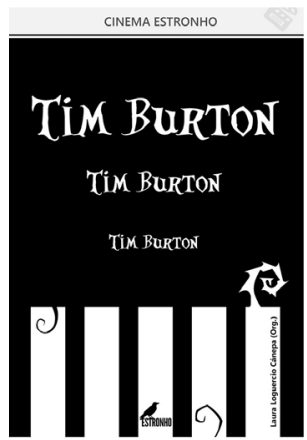

Resumo: O livro organizado por Laura Loguercio Cánepa traz análises da obra de Tim Burton. Em seus 23 capítulos, em ordem cronológica, cada autor escreve acerca de um trabalho específico ou, algumas vezes, sobre um pequeno conjunto deles. É uma reunião de ensaios que possuem uma diversidade de visões estéticas/políticas, com abordagens mais acadêmicas ou mais críticas sobre a obra deste diretor.

Palavras-chave: Cinema; Hollywood; Tim Burton.

Abstract: Different brazilian visions about Tim Burton - The book organized by Laura Loguercio Cánepa brings analyzes of Tim Burton's work. In its 23 chapters, in chronological order, each author writes about a specific work or sometimes about a small set of them. The book is a set of essays with a diversity of esthetic/political visions, whose approach to the director's work is academic or critical.

Keywords: Cinema; Hollywood; Tim Burton.

A recorrência de temas é um sinal da crise criativa dos nossos tempos ou um estilo próprio, uma "visão de mundo" que distingue um cineasta dos demais, garantindo-lhe o título de autor? Essa é uma das questões que transpassam o livro Tim Burton, Tim Burton, 
Tim Burton, organizado por Laura Loguercio Cánepa, professora doutora e coordenadora do Programa de Pós-Graduação em Comunicação da Universidade Anhembi Morumbi, que desde o início de sua carreira acadêmica e de crítica esteve ligada à produção de Burton. O livro faz parte da coleção de cinema da editora Estronho, que reúne desde ensaios informais a teses adaptadas no campo dos estudos cinematográficos.

Em seus 23 capítulos, cada um escrito por um autor diferente, o livro traz análises do trabalho de Tim Burton, que, além de longas-metragens, também realizou programas e filmes feitos para TV, curtas-metragens, videoclipes, exposição de arte e livro de contos. As obras aparecem em ordem cronológica, de maneira que cada autor praticamente escreve sobre um trabalho específico e, algumas vezes, sobre um pequeno conjunto deles.

O livro constitui uma reunião de ensaios que possuem uma diversidade de visões estéticas/políticas, com abordagens mais acadêmicas ou mais críticas sobre a obra de Burton. Seu título é uma referência ao personagem Beetlejuice - interpretado por Michael Keaton na comédia Os Fantasmas se Divertem (1988) -, que, ao ter seu nome repetido por três vezes, pode se libertar do mundo dos mortos para habitar o mundo dos vivos; esse personagem é a primeira criação de Burton a se tornar um fenômeno da cultura pop e da indústria do entretenimento.

O projeto gráfico do livro, com suas bordas pretas e com pequenas ilustrações que emolduram o texto em um frame, segue a identidade visual contrastada de Burton. O volume também possui grande quantidade de referências visuais, com fotos de arquivos, ilustrações e fotos de divulgações de bastidores e de cenas de todos os trabalhos, até mesmo do último longa-metragem, intitulado O Lar das crianças peculiares (2016), lançado posteriormente à finalização do livro. Contudo, o sumário em forma de uma espiral em preto e branco dificulta um pouco uma consulta mais rápida.

No capítulo O maravilhoso mundo de Tim Burton, Rosana de Lima Soares, professora livre-docente da Escola de Comunicações e Artes da Universidade de São Paulo - ECAUSP, faz um belo ensaio que se pretende uma apresentação da coletânea de textos. A autora aponta a premissa da crítica cultural que "deve não apenas estabelecer critérios de qualidade por meio da hierarquização de valores, mas também auxiliar na compreensão das obras artísticas, oferecendo ao público chaves de leitura para sua interpretação e para ampliação de seus repertórios". E é exatamente isso que ela faz a partir de conceitos como estigma, narrativa, preconceitos e mito, a fim de nos conduzir à pergunta: "como é que a linguagem pode ser pensada"? (KRISTEVA apud SOARES, 2016, p. 12).

No segundo capítulo, a organizadora do livro, Laura Cánepa, introduz a relação entre vida e obra, apontando fatores da história pessoal do diretor:

Ainda que análise biográfica nem sempre seja a forma mais adequada para examinar-se a carreira de um artista, o fato é que essas e outras circunstâncias da vida de Burton se repetem em seus filmes, seja pela recorrência dos cenários 
suburbanos, seja pela caracterização de personagens fisicamente semelhantes. (CÁNEPA, 2016, p. 22).

Essa relação se repete em outras análises que apontam, por exemplo, o personagem homônimo do filme Edward Mãos de Tesoura (1990) como sendo um alter ego do diretor, afirmando o caráter autobiográfico dos trabalhos de Burton. O mesmo ocorre com o personagem homônimo do curta-metragem Vicent (1982) e também com o personagem Willy Wonka de A Fantástica Fábrica de Chocolate (2005), em que o ator Johnny Depp também é apontado como uma espécie de alter ego do diretor. Alguns malabarismos argumentativos são realizados a fim de justificar, nesta linha de raciocínio, a presença de filmes como as duas edições de Batman (1989, 1992).

Genio Nascimento, no texto sobre a animação Frankenweenie (2012), baseada no curta-metragem homônimo (1984), mostra-nos que o biógrafo de Burton, Ken Hanke, segue o mesmo caminho de encontrar na obra do diretor elementos biográficos. Em suas palavras: "parece que Burton tem apenas um único tema, ele mesmo. Felizmente, esse é um tema extremamente interessante" (HANKE, 1999, p. 18 apud CÁNEPA, 2016, p. 167).

Uma unanimidade entre os autores do livro é o fato de que Tim Burton tem um estilo próprio e que criou seu universo exclusivo com temas recorrentes. Fernando Oriente demostra alguns elementos centrais da obra do diretor que também são trabalhados por outros autores da coletânea.

A construção das tramas a partir de elementos fantásticos, o humor ácido e sarcástico, o forte apelo visual a partir do qual ele desenvolve suas narrativas, a importância dramática dos cenários, ambientes e espaços cênicos, as referências aos filmes B de horror e ficção científica (principalmente longas americanos dos anos 50 e algumas produções de Roger Corman), a influência marcante da estética expressionista alemã dos ano 20, o flerte com o gótico e a fusão permanente entre uma caricaturização da realidade com o universo da fantasia, da fábula e do extraordinário. (ORIENTE, 2016, p. 43).

Na análise de Sweeney Todd (2007), Gelson Santanna (2016, p. 140) afirma que "o universo de Tim Burton não é o das histórias originais, ele parte sempre de histórias que já foram contadas em algum outro meio: literário, quadrinhos, seriado televisivo, musical, filme. Ele reconta as histórias já contadas ou já mostradas". Beatriz Saldanha enfatiza o diálogo do trabalho de diretor com o dos contos de fadas - como, por exemplo, no filme feito para televisão, intitulado Hansel e Gretel (João e Maria, 1982) - e nos aponta na pesquisa de Vladimir Propp a frequência com que os contos infantis tratam de rituais associados ao reino dos mortos. Apesar da temática e do imaginário do cinema de horror, os elementos são trabalhados sob uma perspectiva mais lúdica do que assustadora.

A questão da repetição temática é retomada por Rodrigo Carreiro (2016, p. 99) no texto sobre A lenda do cavaleiro sem cabeça (1999), ao indagar se: “adotar padrões recorrentes de 
estilo, que se repetem em diversos filmes (muitas vezes com variações mínimas ou discretas), é uma atitude criativa? [...] ou se isso não passa de um mero repetidor, um copista de luxo?". A discussão fica entre o apontamento de uma assinatura visual ou de uma preguiça criativa, o que seria uma característica de um cinema pós-moderno que não tem como objetivo romper com movimentos anteriores, mas se tornar um tipo de colagem descontextualizada das estéticas, técnicas ou narrativas, fazendo uma interseção com diversas correntes sem se limitar a alguma específica.

Além das análises biográficas, boa parte dos textos desenvolve análises comparativas entre as adaptações e os trabalhos originais. Também aponta para altos e baixos na carreira do diretor, que, apesar de produzir blockbusters com lucros milionários, também possui alguns fracassos de público e crítica, tais como Marte Ataca! (1995), Planeta dos Macacos (2001), entre outros. "Frankenweenie também faz parte de uma série de refilmagens feitas por Tim Burton de outros filmes, o que levou alguns críticos a atribuírem ao diretor uma espécie de crise de sua capacidade inventiva" (NASCIMENTO, 2016, p. 171). Alguns autores ressaltam o caráter inventivo e experimental do diretor, que desenvolveu sua própria forma original de fazer cinema, mesmo dentro da indústria, não seguindo alguns dos cânones comerciais; contudo, por outra via, ele mantém em todos os seus trabalhos uma narrativa clássica, um herói central com uma linearidade de enredo.

Sem buscar resolver se Tim Burton é ou não uma voz "autoral" em Hollywood ou uma fórmula que se repete, a coletânea dá seu trabalho por ilustrativo de algumas mudanças na indústria do cinema norte-americano ocorridas desde os anos 1980. Marina Costa, por exemplo, aborda a inserção do diretor no mundo dos videoclipes e cita Arlindo Machado para enumerar a gama de diretores que realizaram esse percurso do cinema para o videoclipe, graças à mudança no conceito de videoclipe, que passa de produto promocional a autoral. Assim, o livro auxilia no entendimento do lugar do realizador na história do cinema contemporâneo.

Os textos também tratam do livro de poemas e da trajetória de Burton como artista plástico. Bruno Anselmi Matangrano escreve sobre O Triste Fim do Pequeno Menino Ostra e outras histórias, publicado nos Estados Unidos em 1997 e, no Brasil, em 2007. Trata-se de poemas curtos ilustrados sobre três personagens - Menino Palito, Menino Ostra e Menino Mancha - que "servem como bons exemplos das personagens deslocadas, desajustadas e melancólicas, tipicamente burtonianas, encontradas nos outros poemas, em seus filmes, gravuras e obras diversas..." (MATANGRANO, 2016, p. 197). Finalizando a coletânea, Fabio Yamaji traça a trajetória de Burton artista plástico, marcada por livros de ilustrações, exposição no MoMa (cuja itinerância ao Brasil, projeto com polaroides, série de desenhos em guardanapos de bar e trabalhos de ilustração para a Disney). Por também abordar sua formação e biografia, tal como em outros textos, alguns assuntos se repetem.

Nem todos os artigos se atêm à linguagem cinematográfica propriamente dita (enquadramento, ângulos, movimentos de câmeras, montagem, etc.). Em suma, a obra traz 
à luz a trajetória de um importante realizador da indústria cinematográfica hollywoodiana contemporânea e se apresenta como uma importante fonte de informações acerca de sua obra e das transformações ocorridas nessa indústria desde a década de 1980. Ademais, o livro contribui positivamente para a formação do público de cinema no Brasil, que é muito carente de obras deste tipo, escritas por autores brasileiros. Nesta época de crise da crítica, esta publicação é uma ótima maneira de entrar em contato com a obra de Tim Burton ou de revisitá-la.

Felipe Neves é professor e mestre em Comunicação e Semiótica, especialista em Cinema e Vídeo, bacharel em Comunicação Social Habilitação em Rádio e TV, realizador audiovisual e documentarista.

felipe.neves170@gmail.com 